\title{
Factors Associated with Condom Use among African American and Hispanic/ Latino Youth
}

\author{
Bianca Gleton ${ }^{1}$, Shayesteh Jahanfar ${ }^{1 *}$, Jeffery Inungu ${ }^{1}$, Christopher Latty ${ }^{1}$
}

${ }^{1}$ Central Michigan University, USA
${ }^{*}$ Corresponding Author: jahan2s@cmich.edu

Citation: Gleton, B., Jahanfar, S., Inungu, J. and Latty, C. (2020). Factors Associated with Condom Use among African American and Hispanic/ Latino Youth. European Journal of Environment and Public Health, 4(1), em0033. https://doi.org/10.29333/ejeph/5954

\section{ARTICLE INFO}

Received: 30 Aug. 2019

Revised: 03 Sep. 2019

Accepted: 04 Sep. 2019

\begin{abstract}
Introduction: Research has shown that African American and Hispanic/Latino youth are at an increased risk of contracting STIs/STDs and HIV/AIDS.
\end{abstract}

Objective: The purpose of this study was to examine factors associated with condom use among African American and Hispanic/Latino youths.

Results: Among African American youth, condom use was more likely among males (2.09; 95\% CI:1.45-3.02) compared to females and less likely among gays/lesbians compared to heterosexuals ( 0.33 ; $95 \% \mathrm{CI}$ : $0.12-0.90)$, adjusted for cofounders. Among Hispanic/Latino youth, condom use was more likely among males (1.70; 95\% CI: $1.25-2.31)$ compared to females and less likely among gays/lesbians (0.16; $95 \% \mathrm{CI}$ : $0.57-0.44)$ and those who used alcohol/drugs during last sex (0.54; 95\% CI: 0.37-0.78), adjusted for cofounders.

Conclusion: For both racial groups', females and those identifying as gay or lesbian were more at risk of not using condoms. For Hispanic/Latino youth who used alcohol/drugs during last sex they were more at risk of not using a condom. This study can be used to identify culturally appropriate interventions that must be implemented to encourage greater condom use amongst African American and Hispanic/Latino youth.

Keywords: condom use, African American, Hispanic/ Latino, youth

\section{INTRODUCTION}

HIV/AIDS is a disease that affects many people globally. In 2016, approximately 36.7 million people were living with HIV around the world (Centers for Disease Control [CDC], 2017). According to the CDC (2017) an estimated 1.1 million people were living with HIV at the end of 2015 in the U.S. However, of those diagnosed with HIV/AIDS, African Americans and Hispanics/Latinos were affected at a disproportioned rate compared to other racial groups. Hispanic/Latinos accounted for $26 \%$ of the 40,324 new HIV diagnoses in the United States, yet they constituted for $17.6 \%$ of the U.S. population (CDC, 2016). Additionally, African Americans accounted for $45 \%$ of HIV diagnoses, though they comprised $12 \%$ of the U.S. population (CDC, 2015). More specifically, African American and Hispanic/Latino youth are greatly affected by HIV/AIDS.

To prevent the spread of sexually transmitted infections and diseases education and interventions must occur early in individuals' lives. For example, $46 \%$ of high school students reported being sexually active (CDC, 2008). Furthermore, 34\% of currently sexually active high school students did not use a condom during their last sexual encounter (CDC, 2010). In
2015 , youth ages 13 to 24 accounted for $22 \%$ of all new HIV diagnoses in the United States (CDC, 2015). According to Vagi et al. (2015) findings from the 2013 Youth Risk Behavior Survey $17.2 \%$ of high school-aged Latino youth have experienced physical and/or sexual dating violence victimization in the past year at rates that are significantly higher than that reported by non-Latino White youth. Kann et al. (2014) indicated that African American youth are more likely to be hit, slapped or hurt by their partners compared to white youth. Dating violence makes it more difficult for these adolescents to negotiate using a condom with their partner.

For many years HIV/AIDS has been an issue affecting individuals globally and in America. HIV/AIDS diagnoses among adults and teenagers is a concern in America. Teenagers account for more newly diagnosed cases of HIV in the USA. It is imperative for researchers to examine various factors associated with condom use among African American and Hispanic/Latino youth, to educate adolescents about the use of condoms to prevent unwanted pregnancies and the spread of HIV/AIDS and other STIs/STDs. Therefore, the purpose of this study is to examine various factors that affect condom use among African American and Hispanic/Latino 
youth. The gap that this study intends to address is, identifying factors that affect condom use to inform the development of intervention programs that can encourage greater condom use, and combat negative sexual health behaviors that put African American and Hispanic/Latino youth at an increased risk for contracting HIV/AIDS and other STIs/STDs.

\section{LITERATURE REVIEW}

As mentioned above, dating violence is a factor that can impact condom use. Several research articles examined the relationship between dating violence and condom use among black and Hispanic/Latino youth. Wingood et al. (2001) examined the association between having a history of dating violence (defined as having a physically abusive boyfriend) and sexual health among 522 black female adolescents. The study compared adolescents who reported experiencing dating violence and those who reported not experiencing dating violence. Those who experienced dating violence were half as likely to have used condoms consistently, and more likely to have contracted a STI, compared to adolescents who reported not experiencing dating violence. These findings are similar to Teitelman et al. (2008) who found that adolescent girls who experienced abuse had less power in their relationship and were more likely to use condoms inconsistently. Participants who experienced dating violence were fearful and perceived themselves as not having the ability to negotiate condom practices with their partner(s) (Champion \& Shain, 1998; Davila \& Brackley, 1999; Gutierrez et al., 2000).

When analyzing the association between dating violence and condom use, it is important to consider cultural differences that adolescents' experience, and different beliefs regarding condoms. Alleyne-Green, Coleman-Cowger and Henry (2012) examined how dating violence victimization (being physically hit by a partner) and dating violence perpetration (physically hitting a partner) were associated with condom use among black and Hispanic adolescent girls. Hispanic youth reported greater incidence of being victims of dating violence, while blacks reported significantly higher levels of perpetration of dating violence. This finding could possibly suggest that black adolescents are perpetrating violence in self-defense, which is consistent with other research findings (Capaldi \& Owen, 2001; Milan et al., 2005; Whitaker et al., 2007). Girls who reported being physically abusive towards their partner and being hit by their partner were more likely to report having sex at earlier ages, drinking during most recent sexual encounter, and not using condoms consistently.

In addition to dating violence, marijuana and alcohol use affect condom use among youth. Stueve and O’Donnell (2005) examined black and Hispanic youth, analyzing the relation between those who engaged in early alcohol use, and subsequent alcohol and sexual behaviors at $7^{\text {th }}$ and $10^{\text {th }}$ grade. Females who used alcohol by $7^{\text {th }}$ grade were more likely than non-initiators to report recent sexual intercourse as $10^{\text {th }}$-grade students. Storholm et al. (2018) discovered that adolescents who used marijuana and alcohol were more likely to report not using a condom during last sex and using condoms inconsistently. Kingree and Betz (2003) examined alcohol and marijuana use among black adolescent males who were detained in juvenile centers. In the study, $45 \%$ of participants used marijuana while $11 \%$ used alcohol. Participants who used marijuana and had negative attitudes towards condoms were less likely to use condoms. However, alcohol use was not associated with condom use. This finding differs from the finding by Swartzendruber, Sales, and Brown (2016), who examined black female adolescents who used marijuana and or alcohol. Adolescent girls who used alcohol were less likely to use condoms. These findings may infer that the use of alcohol may affect black males and females' intent to use condoms differently.

Dating violence and marijuana and alcohol use have been shown to impact adolescents' sexual behavior. In addition to those variables, the age at first sexual intercourse can also influence adolescents' sexual behavior, making them more susceptible to pregnancy, STIs and HIV/AIDS. According to Kaestle et al. (2005), Biello et al. (2013), early age of first sexual intercourse has been shown to be a risk factor for other sexual behaviors and is associated with an increased risk of STI infections. Coker et al. (1994) conducted a cross sectional study on early initiation of sexual intercourse amongst black and white adolescents. The study concluded that compared to white adolescents, black adolescents were more likely to have had their first sexual encounter before the age 13. Participants who initiated sex earlier had a greater number of sexual partners and were 50\% less likely to have used condoms regularly, and seven times more likely to have been pregnant or caused a pregnancy. Early sexual initiation, for both males and females was associated with being drunk or high during last sexual intercourse, having had unprotected intercourse, and pregnancy.

It is important to realize gender and cultural differences that impact the age of first sexual intercourse among adolescents. According to Upchurch et al. (1998), socioeconomic conditions affect the age of first sexual experience. Cultural influences may contribute to these differences between Hispanic/Latino and black populations. For instance, Pflieger et al. (2013) found that black and Hispanic girls are most at risk for STIs in young adulthood. Therefore, when developing intervention programs, it is imperative that these programs account for cultural differences, and employ the best educational methods to effectively educate these adolescents about the consequences associated with sex at an early age, and target adolescents at a younger age. Continuous research regarding youths' sexual behavior will help identify various ways to encourage better sexual health practices amongst adolescents, specifically blacks and Hispanic/ Latino youth who are at greater risk. Adolescents continue to have the highest rates of STIs in the U.S. and adolescent pregnancy rates remain higher in the U.S. than in any other industrialized country (Ventura et al. 2011). Therefore, as mentioned previously, future researchers should continue to design innovative interventions to influence blacks and Hispanic/Latino youth to use condoms.

\section{METHODS}

Data from the 2015 Youth Risk Behavior Surveillance System (YRBSS) was analyzed. The survey used a three-stage cluster sample design to produce a representative sample encompassing data from all public, catholic and other private 
schools from $9^{\text {th }}$ through $12^{\text {th }}$ grade throughout the United States. YRBSS monitors behavior contributing to unintentional injuries and violence, sexual behaviors leading to pregnancy, STI and HIV infections, tobacco use, unhealthy dietary behavior, and lack of physical activity. The YRBSS assesses youths' physical and sexual health behaviors. More than 15,000 U.S. high school students participated in which surveys were conducted in 37 states and 19 large urban school districts.

The first-stage sampling frame consisted of 1,259 primary sampling units (PSUs), consisting of counties, subareas of large counties, or groups of smaller, adjacent counties. The 1,259 PSUs were categorized into 16 strata according to their metropolitan statistical area (MSA) status (e.g., urban city) and the percentages of black and Hispanic students in the PSUs. From the 1,259 PSUs, 54 were sampled with probability proportional to overall school enrollment size for the PSU. In the second stage of sampling, 180 schools with any of grades 9-12 were sampled with probability proportional to school enrollment size from within the 54 PSUs. The third stage of sampling consisted of random sampling in each of grades 912 , one or two classrooms from either a required subject (e.g., English or social studies) or a required period (e.g., homeroom or second period). All students in sampled classes were eligible to participate. Schools, classes, and students that refused to participate were not replaced.

A weighting factor was applied to each student record to adjust for nonresponse. The final overall weights were scaled so the weighted count of students was equal to the total sample size, and the weighted proportions of students in each grade matched population projections for each survey year. There was a total of 1,667 African American and 2,365 Hispanic/Latino youth.

\section{DATA COLLECTION}

The YRBSS surveys were administered to students in a school setting. For most, state, territorial, tribal and large urban school districts, surveys were administered by trained data collectors who traveled to each participating school. A standardized script was read to students by the data collectors. Parental permission was needed before administering the survey in any school. Students' privacy was maintained by allowing anonymous and voluntary participation. Schools were selected systematically with probability proportional to enrollment in grades 9-12 using a random start. One hundred and eight schools were sampled. Puerto Rico, the trust territories, and the Virgin Islands were excluded from the school sampling frame. Those who did not complete the survey or did not receive parental consent were excluded. Systematic equal probability sampling with a random start was used to select classes from each school that participated in the survey.

\section{MEASURES}

This paper examines, dating violence, (physical, and sexual abuse) within the past 12 months, drug or alcohol use during last sexual intercourse and early initiation of sexual intercourse to determine their effects on condom use among African American and Hispanic/Latino youth. Physical and sexual abuses were assessed by asking youth "how many times in the past 12 months have you been physically hit by someone you were dating or going out with?” Forced sexual intercourse was also assessed by asking participants, "Have you ever been forced to do something sexually?” To assess drug or alcohol use participants were asked if "alcohol or drugs were used during last sexual intercourse?” To assess age of first sexual intercourse participants were asked "how old were you when you had sexual intercourse for the first time? To assess condom use during last sex, participants were asked, "the last time you had sexual intercourse, did you or your partner use a condom?”

\section{DATA ANALYSIS}

Data analysis was comprised of several sequential steps. First, descriptive statistics were used to describe the sample characteristics. The sample characteristics included age, gender, sexual identity, grade level, and age of fist sexual intercourse. Additionally, chi square testing was done analyzing the association between condom use, dating violence and alcohol/drug use and age of first sexual intercourse. After chi square identified statistically significant and non-significant variables associated with having used a condom during last sexual intercourse, the variables that were statistically significant in chi square testing $(\mathrm{P}<0.05)$ were included in binary regression analysis. Model statistics computed and included unadjusted and adjusted odds ratio and $95 \%$ confidence intervals.

\section{RESULTS}

Table 1 shows the demographic factors and descriptive statistics of African American and Hispanic/Latino youth sample. Among the sample, (41.3\%) were African American and (58.6\%) were Hispanic/Latino. Of African American youth, (49.5\%) were between the ages of $15-16$ and (51\%) of Hispanic/Latino youth were between those ages. Table 2 shows bivariate analysis, comparing age, gender, sexual identity, grade level, used alcohol/drugs during last sex and physical and sexual abuse with condom use. Table 3 demonstrates unadjusted and adjusted regression models identifying significant variables pertaining to condom use among African American youth. Among African American youth, condom use was more likely among males (2.09; $95 \%$ CI: 1.45-3.02) compared to females. Condom use was less likely among gays/lesbians compared to heterosexuals (0.33; 95\% CI: 0.12-0.90), adjusted for cofounders. Table 4 demonstrates unadjusted and adjusted regression models identifying significant variables pertaining to condom usage among Hispanic/Latino youth. Among Hispanic/Latino youth, condom use was more likely among males (1.70; 95\% CI: $1.25-$ 2.31) compared to females and less likely among gays/lesbians (0.16; 95\% CI: $0.57-0.44)$ and those who used alcohol/drugs during last sex $(0.54 ; 95 \% \mathrm{CI}$ : $0.37-0.78)$, adjusted for cofounders. Age, age of first sexual intercourse, physical and. sexual abuse was not statistically significant. 
Table 1. Descriptive statistics of African American and Hispanic Sample

\begin{tabular}{|c|c|c|c|c|}
\hline \multirow[b]{2}{*}{ Variables } & \multicolumn{2}{|c|}{ African American } & \multicolumn{2}{|c|}{ Hispanic } \\
\hline & Frequency (N) & Valid Percentage (\%) & Frequency (N) & Valid Percentage (\%) \\
\hline \multicolumn{5}{|l|}{ Age } \\
\hline 14 and below & 161 & 9.7 & 261 & 11.0 \\
\hline $15-16$ & 831 & 49.9 & 1210 & 51.2 \\
\hline 17 and above & 673 & 40.4 & 891 & 37.8 \\
\hline \multicolumn{5}{|l|}{ Sex } \\
\hline Female & 821 & 49.5 & 1183 & 50.2 \\
\hline Male & 837 & 50.5 & 1174 & 49.8 \\
\hline \multicolumn{5}{|l|}{ Sexual Identity } \\
\hline Heterosexuals & 1338 & 89.1 & 2032 & 93.0 \\
\hline Gay or Lesbian & 52 & 3.5 & 47 & 2.2 \\
\hline Bisexual & 111 & 7.4 & 105 & 4.8 \\
\hline \multicolumn{5}{|l|}{ Grade level } \\
\hline $9^{\text {th }}$ grade & 424 & 25.6 & 600 & 25.5 \\
\hline $10^{\text {th }}$ grade & 424 & 25.6 & 623 & 26.5 \\
\hline $11^{\text {th }}$ grade & 423 & 25.5 & 591 & 25.1 \\
\hline $12^{\text {th }}$ grade & 387 & 23.3 & 540 & 22.9 \\
\hline \multicolumn{5}{|c|}{ Age of First Sexual Intercourse } \\
\hline 14 and below & 842 & 61.4 & 1482 & 68.9 \\
\hline $15-16$ & 254 & 18.5 & 272 & 12.7 \\
\hline 17 and above & 275 & 20.1 & 396 & 18.4 \\
\hline \multicolumn{5}{|c|}{ Used Alcohol or Drugs last Sexual Intercourse } \\
\hline Never had sex & 582 & 34.9 & 1264 & 60.0 \\
\hline Yes & 119 & 62.4 & 174 & 8.3 \\
\hline No & 518 & 95.8 & 669 & 31.8 \\
\hline \multicolumn{5}{|c|}{ Physical Abuse While Dating, Past 12 Months } \\
\hline Yes & 557 & 34.9 & 902 & 39.7 \\
\hline No & 1040 & 65.1 & 1370 & 60.3 \\
\hline \multicolumn{5}{|c|}{ Forced to Have Sexual Intercourse } \\
\hline Yes & 126 & 7.9 & 125 & 5.4 \\
\hline No & 1466 & 92.1 & 2184 & 94.6 \\
\hline
\end{tabular}

Table 2. Characteristics of African American and Hispanic youth and the association between condom practices

\begin{tabular}{|c|c|c|c|c|c|c|c|}
\hline Variables & & $\begin{array}{l}\text { African American } \\
\text { Used condom } \\
\text { during last sexual } \\
\text { intercourse } \\
\mathrm{N}(\%)\end{array}$ & $\begin{array}{c}\text { African American } \\
\text { Did not Use } \\
\text { condom during last } \\
\text { sexual intercourse } \\
\text { N (\%) }\end{array}$ & $\begin{array}{l}\text { P-value } \\
\text { African } \\
\text { American }\end{array}$ & $\begin{array}{l}\text { Hispanic/Latino } \\
\text { Used a condom } \\
\text { during last sexual } \\
\text { intercourse } \\
\mathrm{N}(\%)\end{array}$ & $\begin{array}{c}\text { Hispanic/Latino } \\
\text { Did not Use } \\
\text { condom during last } \\
\text { sexual intercourse } \\
\mathrm{N}(\%)\end{array}$ & $\begin{array}{l}\text { P-value } \\
\text { Hispanics }\end{array}$ \\
\hline \multirow{2}{*}{ Gender } & Female & $146(50.5)$ & $143(49.5)$ & \multirow{2}{*}{0.001} & $201(54.5)$ & $168(45.4)$ & \multirow{2}{*}{0.001} \\
\hline & Male & $268(69.6)$ & $117(30.4)$ & & $313(67.5)$ & $151(32.5)$ & \\
\hline \multirow{3}{*}{ Sexual Identity } & Heterosexual & $380(64.4)$ & $210(35.6)$ & \multirow{3}{*}{0.001} & $469(63.2)$ & $273(36.8)$ & \multirow{3}{*}{0.001} \\
\hline & Gay or Lesbian & $6(27.3)$ & $16(72.7)$ & & $6(26.1)$ & $17(73.9)$ & \\
\hline & Bisexual & $19(40.4)$ & $28(59.6)$ & & $23(56.1)$ & $18(43.9)$ & \\
\hline \multirow{4}{*}{ Grade Level } & $9^{\text {th }}$ & $77(74.0)$ & $27(25.9)$ & \multirow{4}{*}{0.012} & $80(70.8)$ & $33(29.2)$ & \multirow{4}{*}{$0.197^{*}$} \\
\hline & $10^{\text {th }}$ & $109(64.5)$ & $60(35.5)$ & & $113(60.8)$ & $73(39.2)$ & \\
\hline & $11^{\text {th }}$ & $107(56.3)$ & $83(43.7)$ & & $138(60.3)$ & $91(39.7)$ & \\
\hline & 12th & $121(57.6)$ & $89(42.4)$ & & $180(59.8)$ & $121(40.2)$ & \\
\hline \multirow{3}{*}{ Age } & 14 and below & $19(61.3)$ & $12(38.7)$ & \multirow{3}{*}{0.02} & $21(65.6)$ & $11(34.4)$ & \multirow{3}{*}{$0.077^{*}$} \\
\hline & $15-16$ & $201(67.0)$ & $99(33.0)$ & & $225(62.7)$ & $134(37.3)$ & \\
\hline & 17 and above & $195(56.4)$ & $151(43.6)$ & & $268(60.5)$ & $175(39.5)$ & \\
\hline \multirow{3}{*}{$\begin{array}{l}\text { Age of First sexual } \\
\text { intercourse }\end{array}$} & 14 and below & $95(57.6)$ & $70(42.4)$ & \multirow{3}{*}{$0.498^{*}$} & $102(56.0)$ & $80(44$. & \multirow{3}{*}{$0.064^{*}$} \\
\hline & $15-16$ & $152(63.3)$ & $88(36.7)$ & & $163(62.9)$ & $96(37.1)$ & \\
\hline & 17 and above & $165(62.3)$ & $100(37.7)$ & & $242(63.2)$ & $141(36.8)$ & \\
\hline \multirow{2}{*}{$\begin{array}{l}\text { Used Alcohol or Drugs } \\
\text { last Sexual Intercourse }\end{array}$} & Yes & $59(51.3)$ & $56(48.7)$ & \multirow{2}{*}{0.014} & $83(50.9)$ & $80(49.1)$ & \multirow{2}{*}{0.003} \\
\hline & No & $316(63.7)$ & $180(36.3)$ & & $413(63.7)$ & $235(36.3)$ & \\
\hline \multirow{2}{*}{$\begin{array}{l}\text { Physical Abuse While } \\
\text { Dating, Past } 12 \text { months }\end{array}$} & Yes & $77(52.7)$ & $69(47.3)$ & \multirow{2}{*}{0.025} & $98(58.0)$ & $71(42.0)$ & \multirow{2}{*}{$0.275^{*}$} \\
\hline & No & $319(63.0)$ & $187(37.0)$ & & $398(62.6)$ & $238(37.4)$ & \\
\hline \multirow{2}{*}{$\begin{array}{l}\text { Forced to Have Sexual } \\
\text { Intercourse }\end{array}$} & Yes & $37(50.0)$ & $37(50.0)$ & \multirow{2}{*}{$0.254^{*}$} & $37(41.1)$ & $53(58.9)$ & \multirow{2}{*}{$0.354^{*}$} \\
\hline & No & $375(62.9)$ & $221(37.1)$ & & $472(64.1)$ & $264(45.9)$ & \\
\hline
\end{tabular}


Table 3. Unadjusted and adjusted odds ratio (OR) and 95\% confidence intervals (95\% CL) of reporting condom use amongst various demographic characteristics of African American youth

\begin{tabular}{|c|c|c|}
\hline Variables & Unadjusted Odd Ratio (95\% Cl) & Adjusted Odd Ratio (95\% Cl) \\
\hline \multicolumn{3}{|c|}{ r } \\
\hline 14 and below & $1.23(0.56-2.60)$ & $0.66(0.21-2.09)$ \\
\hline $15-16$ & $1.57(1.14-2.17)$ & $1.39(0.78-2.46)$ \\
\hline $17+$ & 1.0 & 1.0 \\
\hline \multicolumn{3}{|l|}{ Gender } \\
\hline Male & $2.24(1.63-3.08)$ & $2.09(1.45-3.02)$ \\
\hline Female & 1.0 & 1.0 \\
\hline \multicolumn{3}{|l|}{ Grade Level } \\
\hline $9^{\text {th }}$ & $2.09(1.25-3.52)$ & $2.12(0.85-5.30)$ \\
\hline $10^{\text {th }}$ & $1.34(0.88-2.03)$ & $0.95(0.47-1.93)$ \\
\hline $11^{\text {th }}$ & $0.95(0.64-1.41)$ & $0.80(0.49-1.31)$ \\
\hline 12th & 1.0 & 1.0 \\
\hline \multicolumn{3}{|l|}{ Sexual Identity } \\
\hline Gay or Lesbian & $0.21(0.08-0.54)$ & $0.33(0.12-0.90)$ \\
\hline Bisexual & $0.38(0.20-0.69)$ & $0.53(0.27-1.06)$ \\
\hline Heterosexual & 1.0 & 1.0 \\
\hline \multicolumn{3}{|c|}{ Age of First sexual intercourse } \\
\hline 14 and below & $0.82(0.55-1.22)$ & - \\
\hline $15-16$ & $1.05(0.73-1.50)$ & - \\
\hline 17 and above & 1.0 & - \\
\hline \multicolumn{3}{|c|}{ Used Alcohol or Drugs last Sexual Intercourse } \\
\hline Yes & $0.60(0.40-0.90)$ & $0.70(0.44-1.10)$ \\
\hline No & 1.0 & 1.0 \\
\hline \multicolumn{3}{|c|}{ Physical Abuse While Dating, Past 12 Months } \\
\hline Yes & $0.65(0.45-0.95)$ & $0.75(0.49-1.14)$ \\
\hline No & 1.0 & 1.0 \\
\hline \multicolumn{3}{|c|}{ Forced to Have Sexual Intercourse } \\
\hline Yes & $0.80(0.54-1.80)$ & - \\
\hline No & 1.0 & - \\
\hline
\end{tabular}

Table 4. Unadjusted and adjusted odds ratio (OR) and 95\% confidence intervals (95\% CL) of reporting condom use amongst various demographic characteristics of $\underline{\text { Hispanic/Latino youth }}$

\begin{tabular}{|c|c|c|}
\hline Variables & Unadjusted Odd Ratio (95\% Cl) & Adjusted Odd Ratio (95\% Cl) \\
\hline \multicolumn{3}{|c|}{, } \\
\hline 14 and below & $1.25(0.59-2.65)$ & $0.65(0.24-1.82)$ \\
\hline $15-16$ & $1.10(0.82-1.46)$ & $0.86(0.52-1.41)$ \\
\hline $17+$ & 1.0 & 1.0 \\
\hline \multicolumn{3}{|l|}{ Gender } \\
\hline Male & $0.58(0.44-0.77)$ & $1.70(1.25-2.31)$ \\
\hline Female & 1.0 & 1.0 \\
\hline \multicolumn{3}{|l|}{ Grade Level } \\
\hline $9^{\text {th }}$ & $1.63(1.02-2.60)$ & $1.93(0.91-4.10)$ \\
\hline $10^{\text {th }}$ & $1.04(0.72-1.51)$ & $1.19(0.66-2.17)$ \\
\hline $11^{\text {th }}$ & $1.02(0.72-1.45)$ & $1.07(0.68-1.66)$ \\
\hline 12th & 1.0 & 1.0 \\
\hline \multicolumn{3}{|l|}{ Sexual Identity } \\
\hline Gay or Lesbian & $0.21(0.08-0.53)$ & $0.16(0.57-0.44)$ \\
\hline Bisexual & $0.74(0.39-1.40)$ & $0.88(0.44-1.72)$ \\
\hline Heterosexual (Straight) & 1.0 & 1.0 \\
\hline \multicolumn{3}{|l|}{ Age of First sexual intercourse } \\
\hline 14 and below & $0.74(0.52-1.06)$ & - \\
\hline $15-16$ & $0.99(0.71-1.37)$ & - \\
\hline 17 and above & 1.0 & - \\
\hline \multicolumn{3}{|c|}{ Used Alcohol or Drugs last Sexual Intercourse } \\
\hline Yes & $0.59(0.42-0.84)$ & $0.54(0.37-0.78)$ \\
\hline No & 1.0 & 1.0 \\
\hline \multicolumn{3}{|c|}{ Physical Abuse While Dating, Past 12 Months } \\
\hline Yes & $0.83(0.59-1.17)$ & - \\
\hline No & 1.0 & - \\
\hline \multicolumn{3}{|l|}{ Forced To Have Sexual Intercourse } \\
\hline Yes & $0.85(0.60-1.20)$ & - \\
\hline No & 1.0 & - \\
\hline
\end{tabular}




\section{DISCUSSION}

\section{Gender}

Gender was associated with non- condom use among African American and Hispanic/Latino youth. For both, African American and Hispanic/Latino youth males were more likely to report using condoms during their most recent sexual encounter compared to their female counterparts. Deardorff et al. (2013) found that among Latino female adolescents, feeling comfortable talking about sex with a partner was positively associate with frequency of direct commination to foster condom use. If female youth have the ability to negotiate condoms use and the education along with their partners on why condoms are important this could possibly encourage greater condom use. There is a need for intervention programs that focuses on empowering and educating female youth on how to negotiate condoms use in their relationship with their partner.

\section{Sexual Identity}

Sexual identity was associated with non-condom use among African American and Hispanic/Latino youth. Those who identified as gay or lesbian were less likely to use condoms compared to heterosexuals. Mustanski et al. (2015) studied condom use among adolescent gay and bisexual males, finding that many gay guys don't use condoms because of the perception that they can't get pregnant from gay sex. According to the Centers for Disease Control, in 2016 among all gay and bisexual men who received an HIV diagnosis in the United States, Hispanics/Latinos accounted for the secondhighest number $(7,689 ; 29 \%)$, following African Americans (10,226; 38\%). Whites accounted for 7,392 (28\%), and other races/ethnicities accounted for 1,537 (6\%).

\section{Age of First Sexual Intercourse}

For both, African American and Hispanic/Latino youth, age of first sex was not associated with condom use. It was hypothesized that the younger and individual is when they first have sex the greater the chances of them not using protection due to the lack of sexual health knowledge. However, for both racial groups over half of the sample expressed first having sex at age 17 and above. Therefore, the older a person is the more knowledge they may have about condom use being more inclined to use condoms.

\section{Physical Abuse and Sexual Abuse}

Among African American youth, physical and sexual abuse was not associated with condom use. These results differ from (Gutierrez et al., 2000) study on how dating violence affects condom use. An explanation for why there was no association is that a larger percentage, (63.0\%) indicated they had not been physically abused and used condoms during last sex. Likewise, (62.9\%) indicated they had not been forced to have sex and used a condom during last sex. The same results are very similar for Hispanic/Latino youth. Majority reported not being physically and sexually abused by a partner during last sex. Wingood \& DiClemente, (2000) discovered that youth who experience abuse used condoms inconsistently, and had less power in a relationship.

\section{Used Alcohol/Drugs during Last Sex}

Among African American youth, used drug/alcohol during last sex was not associated with condom use. A reason why there may have not been an association is because (63.7\%) indicated that they did not use alcohol/during last sex and a condom was used. However, among Hispanic/Latino youth this factor was associated with non-condom use. These findings have been previously reported by Storholm et al., (2018), whom discovered that adolescents who used alcohol were more likely to report not using a condom during last sex. 54\% of Hispanic females who used drugs or drank alcohol during last sexual intercourse did not use a condom, compared to $46 \%$ of Hispanic males who used drugs or drank during last sexual intercourse and did not use a condom as well. Therefore, educating youth, on the importance of not engaging in risky sexual behaviors when using drugs and alcohol is essential to help reduce unintended consequences.

\section{LIMITATIONS}

This study is a cross-sectional research deign, which precludes identification of casual relationships. Furthermore, a strength of this study is that it was a representative sample of youth from all areas across the United States. The results can be generalized. However, the dataset did not provide a question assessing youths' HIV/AIDS knowledge. Had that question been asked an association between HIV/AIDS knowledge and condom use could have been examined to determine how knowledge affects condom use as well. Lastly, self-report is not always accurate. When sensitive questions such as, physical and sexual abuse is asked participants may not report truthful information, which could cause response bias. Physiological abuse was not assessed, which is another limitation to help identify how physiological abuse is associated with condom use.

\section{CONCLUSION}

From the statistics presented, one can identify the need to educate, and promote healthy sex practices among African American and Hispanic/Latino youth. For both, African American and Hispanic/Latino youth, interventions should focus on educating female youth on how to negotiate condom use with their partner. From this study, gay and lesbian African American and Hispanic/Latino youth were least likely to use condoms compared to heterosexuals. Future research must examine what interventions could be implemented to encourage these groups of people to practice safer sex For Hispanic/Latino youth who used drugs/alcohol and engage in sexual intercourse there must be programs and or interventions designed that educate youth on how alcohol and drugs can affect their intent to use condoms. Ultimately, these interventions should strive to prevent youth from engaging in sexual behaviors when using alcohol and drugs. Lastly, for both racial groups there should be interventions that focus on reducing dating violence. All these interventions could sever as a method to help decrease STI/STD and HIV/AIDS transmission within these two racial groups. Lastly, culturally appropriate interventions are essential. What is effective for one race is not always effective for another. 


\section{REFERENCES}

Alleyne-Green, B., Coleman-Cowger, V. H., \& Henry, D. B. (2012). Dating violence perpetration and/or victimization and associated sexual risk behavior among a sample of inner-city African American and Hispanic adolescent youth. Journal of Interpersonal Violence, 27(8), 1457-1474. https://doi.org/10.1177/0886260511425788

Biello, K. B., Ickovics, J., Niccolai, L., Lin, H., \& Kershaw, T. (2013). Racial Differences in Age at First Sexual Intercourse: Residential Racial Segregation and the BlackWhite Disparity among U.S. Adolescents. Public Health Reports, 128(1), 23-32. https://doi.org/10.1177/ $00333549131282 \mathrm{~S} 103$

Breiding, M. J., et al. (2014). Prevalence and characteristics of sexual violence, stalking, and intimate partner violence victimization--national intimate partner and sexual violence survey, United States, 2011. Morbidity and Mortality Surveillance Summaries, 63(8), 1-18. Retrieved from

https://www.ncbi.nlm.nih.gov/pmc/articles/PMC4692457/

Brook, J. S., Balka, E. B., \& Whiteman, M. (1999). The risks for late adolescence of early adolescent marijuana use. American Journal of Public Health, 89(10), 1549-1554. https://doi.org/10.2105/AJPH.89.10.1549

Capaldi, D. M., \& Owen, L. D. (2001). Physical aggression in a community sample of at risk young couple: gender comparisons for high frequency, injury and fear. Journal of Family Psychology, 15(3), 425-440. https://doi.org/10.1037/0893-3200.15.3.425

Center for Disease Control. (2016). HIV and Hispanics/Latinos. Retrieved from https://www.cdc.gov/hiv/group/ racialethnic/hispaniclatinos/index.html

Centers for Disease Contorl. (2018). Teen dating violence. Retrieved from https://www.cdc.gov/violenceprevention/ intimatepartnerviolence/teen_dating_violence.html

Centers for Disease Control. (2015). HIV among Youth. Retrieved from https://www.cdc.gov/hiv/group/age/youth/ index.html

Champion, J. D., \& Shain, R. N. (1998). The context of sexually transmitted diseases: Life histories of woman abuse. Issues Mental Health Nursing, 25(5), 293-316. https://doi.org/10.1080/016128498248908

Coker, A. L, Richter, D. L., Valois, R. F., McKeown, R. E. Garrison, C. Z., \& Vincent, M. L. (1994). Correlates and consequence of early initiation of sexual intercourse. Journal of School Health, 65(9), 372-377. https://doi.org/10.1111/j.1746-1561.1994.tb06208.x

Davila, Y. R., \& Brackley, M. H. (1999). Mexican and Mexican American women in battered women's shelter: barriers to condom negotiation for HIV/AIDS prevention. Issues Mental Health Nursing, 20(4), 333-355. https://doi.org/10.1080/016128499248529

Deardorff, J., Tschann, J. M., Flores, E., de Groat, C. L., Steinberg, J. R., \& Ozer, E. J. (2013). Latino youths' sexual values and condom negotiation strategies. Perspectives on sexual and reproductive health, 45(4), 182-90. https://doi.org/10.1363/4518213
Dosomething.org. 11 facts about teen dating violence. (2018). Retrieved from https://www.dosomething.org/us/facts/11facts-about-teen-dating-violence

Gutierrez, L. M., Hyun, Oh, H. J., \& Gillmore, M. R. (2000). Toward an understanding of (em) power (ment) for HIV/AIDS prevention with adolescent women. Sex Roles, 42(7), 581-611. https://doi.org/10.1023/A:1007047306063

Jemmott, J. B., Jemmott, L. S., \& Fong, G. T. (1992) Reduction in HIV risk-associated sexual behaviors among male adolescents: Effects of an AIDS prevention intervention. American Journal of Public Health, 82(3), 372-377. https://doi.org/10.2105/AJPH.82.3.372

Kaestle, C. E., Halpern, C. T., Miller, W. C., \& Ford, C. A. (2005). Young age at first sexual intercourse and infections in adolescents and young adults. American Journal of Epidemiology, 161(8), 774-780. https://doi.org/10.1093/aje/ kwi095

Kann, L., Kinchen, S., Klin, S., et al. (2014). Youth risk behavior surveillance, United States, 2013. MMWR Weekly Report, 63(SS04), 1-168.

Kingree, J. B., \& Betz, H. (2003). Risky sexual behavior in relation to marijuana and alcohol use among AfricanAmerican, male adolescent detainees and their female partners. Drug and Alcohol Dependence, 2(24), 197-203. https://doi.org/10.1016/S0376-8716(03)00196-0

Kirby, D. B., Baumler, E., Coyle, K. K., Basen-Engquist, K., Parcel, G. S., Harrist, R., \& Banspach, S. W. (2004). The "Safes Choices" intervention: its impact on the sexual behaviors of different subgroups of high school students. Journal of Adolescent Health, 35(6), 442-452. https://doi.org/10.1016/j.jadohealth.2004.02.006

Milan, S., Lewis, J., Ethier, K., Kershaw, T., \& Ickovics, J. R. (2005). Relationship violence among adolescent mothers: Frequency, dyadic nature and implication for relationship dissolution and mental health. Psychology of Women Quarterly, 29(3), 302-312. https://doi.org/10.1111/j.14716402.2005.00224.x

Mustanski, B. (2015). Future directions in research on sexual minority adolescent mental, behavioral, and sexual health. Journal of clinical child and adolescent psychology: the official journal for the Society of Clinical Child and Adolescent Psychology, American Psychological Association, Division 53, 44(1), 204-219. https://doi.org/10.1080/15374416.2014. 982756

Nationallatinonetwork.org. (2018). Help Seeking. Retrived from https://nationallatinonetwork.org/learn-more/factsand-statistics/help-seeking

Norris, A. E., \& Ford, K. (1994). Condom beliefs in urban, low income African American and Hispanic youth. Health Education Quarterly, 21(1), 39-53. https://doi.org/10.1177/109019819402100106

Pflieger, J. C, Cook, E. C., Niccolai, L. M., \& Connell, C. M. (2013). Racial ethnic differences in patterns of sexual risk behavior and rates of sexually transmitted infections amongst female adults. American Journal of Public Health, 105(5), 903-909. https://doi.org/10.2105/AJPH.2012. 301005 
Stoler, H., Quadagno, D., Sly, D. F., Riehman, K. S., Eberstrin, I. W., \& Harrison, D. F. (2000). Relationship dynamic, ethnciicty and condom use among low-income women. Journal of Peer Reviewed Research, 32(2), 82-88. https://doi.org/10.2307/2648216

Storholm, E. D., Ewing, B. A., Holiday, S. B., Stein, B. D., Meredith, L. S., Shadel, W. G., \& D'Amico, E. J. (2018). Using marijuana, drinking alcohol or a combination of both: the association of marijuana, alcohol and sexual behavior among adolescents. Sexual Health. https://doi.org/10.1071/SH16218

Stueve, A., \& O’Donnell, L. N. (2005). Early alcohol initiation and subsequent sexual and alcohol risk behaviors among urban youth. American Journal of Public Health, 95(5), 887894. https://doi.org/10.2105/AJPH.2003.026567

Swartzendruber, A., Sales, J. M., Brown, J. L., DiClemente, R. J., \& Rose, E. S. (2016). Comparison of substance use typologies as predictors of sexual risk outcomes in African American females. Archives of Sexual Behavior, 45(1), 66-72. https://doi.org/10.1007/s10508-015-0518-0

Teitelman, A. M., Ratcliffe, S. J., Morales-Aleman, M. M., \& Sullivan, C. M. (2008). Sexual relationship power, intimate partner violence, and condom use among minority urban girls. Journal of Interpersonal Violence, 23(12) https://doi.org/10.1177/0886260508314331
Upchurch, D. M., Levy-Storms, L., Sucoff, C. A., \& Aneshensel, C. S. (1998). Gender and ethnic differences in the timing of first sexual intercourse. Family Planning Perspectives, 30(3), 121-127. https://doi.org/10.2307/2991625

Vagi, K. J., O’Malley, O. E., Basile, K. C., \& Vivolo-K.antor., A. M. (2015). Teen Dating violence physical and sexual among high school students: findings from the 2013 national youth risk behavior survey. Journal of American Medical Association, 169(5), 474-482. https://doi.org/10.1001/ jamapediatrics.2014.3577

Ventura, S. J., Mathews, T. J., Sutton, P. D., \& Abma, J. C. (2011) Adolescent pregnancy and Childbirth United States, 1991-2008. Morbidity and Mortality Supplements, 60(1), 1117. Retrieved from https://www.cdc.gov/mmwr/preview/ mmwrhtml/su6001a23.htm

Whitaker, D. J., Haileyesus, T., Swahn, M., \& Saltzman, L. S. (2007). Differences in frequency of violence and reported injury between relationships with reciprocal and nonreciprocal intimate partner violence. American Journal of Public Health, 97(5), 941-947. https://doi.org/10.2105/AJPH.2005.079020

Wingood, G. M., DiClemente, R. J., McCree, D. H., Harrington, K., \& Davies, S. L (2000). Application of the theory of gender and power to examine HIV-related exposures, risks and effective intervention for women. Health Education Behavior, 107(5), 1-6. https://doi.org/10.1177/ 109019810002700502 